\title{
Dynamic Thermal Rating of a Modular Multilevel Converter HVDC Link with Overload Capacity
}

\author{
Paul D. Judge, Student Member, IEEE and Timothy C. Green, Senior Member, IEEE \\ Department of Electrical and Electronic Engineering \\ Imperial College London, South Kensington, SW7 2AZ, London, United Kingdom \\ e-mail: \{p.judge12,t.green\}@ic.ac.uk
}

\begin{abstract}
The power rating of Modular Multilevel Converter based HVDC has increased rapidly over the past decade, with individual links in the gigawatt power range now technically feasible and further power increases on the horizon. Such large links may be required to provide ancillary services such as fast frequency response or emergency power re-routing in the event of a system disturbance. Providing such services may require converters to be designed with overload capacity. This paper examines how the thermal aspects of semiconductor devices may impact the operation of such converters and how the exploitation of short term thermal dynamics may lead to dynamic rating of converters.
\end{abstract}

Index Terms-Converters, Frequency response, HVDC Transmission, Thermal management of electronics

\section{INTRODUCTION}

Modular Multilevel Converters (MMC) have become the standard Voltage Source Converter (VSC) topology for HVDC applications. The modular topology is constructed from several hundreds of individual Sub-Modules (SM) in a half-bridge or full-bridge arrangement, each with a capacitor controlled around a nominal voltage. By bypassing or inserting SMs within each arm of the converter a voltage waveform with low distortion can be generated whilst keeping the individual switching frequencies of the power semiconductors to a low level [1].

The topology allows converters with power ratings in the gigawatts, operating at several hundred thousand kilovolts, to be constructed using standard IGBT modules and control circuitry designed for drive applications. The available power rating of such converters and associated cable technology has increased rapidly over the past decade. Power ratings are now available that approach or exceed the N-1 loss of in-feed security criterion of many modern power systems. As converters increase in size, and multi-terminal networks become viable, VSC based HVDC systems may be required to provide additional ancillary services such as fast frequency response and emergency power flow control during system disturbances. In order to always have sufficient power handling available to provide these services, MMCs may have to be designed with overload capacity. Such overload capacity is already common with Current Source Converter (CSC) technology [2]. For example the Three Gorges-Changzhou and Three GorgesGuangdon HVDC bipolar links are designed for a nominal

The authors gratefully acknowledge the financial support of the Research Councils UK through the HubNet Project (grant number: EP/I013636/1) rating of $3 \mathrm{GW}$, with a continuous overload rating of 3.48 $\mathrm{GW}$, and a five second overload rating of $4.5 \mathrm{GW}$ [3].

This paper examines how similar overload capabilities could be designed into MMC based HVDC links and how the thermal aspects of the semiconductors devices used may impact or limit the operation of such converters. This paper focuses on an example converter with the specifications given in Table I.

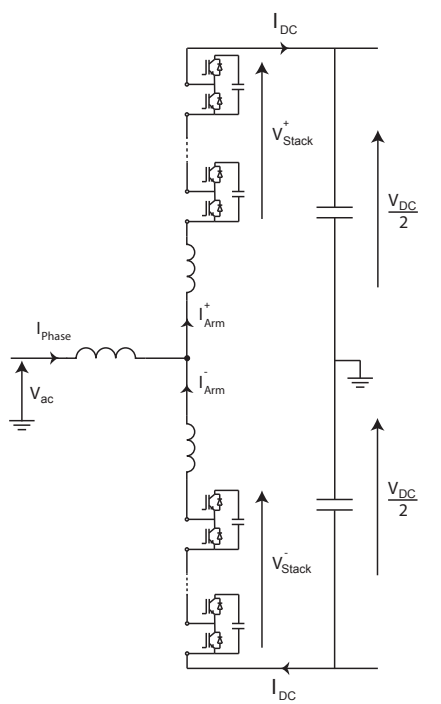

Figure 1: Per Phase Representation of Modular Multilevel Converter

\section{Power Limitations in Modular Multilevel CONVERTERS}

The power range of MMCs are limited by three main factors; the peak arm current, the modulation index of the converter arms and the peak SM voltage $[4,5]$.

- The peak arm current limit is defined as the peak current that the semiconductor switches can safely and reliably switch whilst remaining within their Safe Operating Area (SOA). By operating past this current limit threshold the IGBT module used within the converter is at increased likelihood of failure due to thermal breakdown or latchup.

- The voltage that an MMC can generate is limited by both the DC terminal voltage and by the maximum voltage that 
the sum total of SMs within each arm of the converter can generate. Due to the energy deviation of the SM voltage capacitors the level of voltage available within each arm is a time-varying value. The modulation index $\left(V_{\text {mod }}\right)$ can be defined as in (1). By keeping $V_{\text {mod }}$ within the bounds of $0-1$ the converter ensures it both keeps the generated $\mathrm{AC}$ voltage below the $\mathrm{DC}$ terminal voltage and has enough voltage available to maintain control over the arm and phase currents. For operational regions it is required to add some headroom on this value to allow for control margin. The example converter has been specified to keep $V_{\text {mod }}$ within the bounds of $0.05-0.95$.

$$
V_{\text {mod }}=\frac{V_{\text {stack }} k_{\text {requested }}}{\sum_{i=1}^{n} V_{S M_{i}}}
$$

- The peak SM voltage limit is defined as the maximum allowable voltage, due to SM voltage deviation, that each individual SM within the converter is designed to reach during normal operation [5]. Any voltage reached above this level may require protective control action to be implemented to protect the SM from damage.

\section{A. Overload Technique}

By using techniques, such as those proposed in [6], the PQ envelope of an MMC can be expanded past its normal operational limits when running in its standard mode. These techniques involve controlling the circulating currents within the converter to suppress the peak current flowing through the arms of the converter. This circulating current provides no disturbance to either the AC or DC side waveforms. This paper proposes that such methods could be useful for providing overload capacity within MMC based HVDC schemes without significant over-sizing of the semiconductor devices, with resulting increased capital cost, of the converter stations. The use of circulating currents cause additional losses within the converter and may be unattractive for use during normal operation. However during emergency events, when the converter may be required to operate in the overload region, the efficiency of the converter may not be a high priority for the system operator.

Table I: Converter Specifications

\begin{tabular}{l|c}
\hline Power Rating & $1.26 \mathrm{GW}$ \\
DC Voltage & $\pm 525 \mathrm{kV}$ \\
AC Voltage (L-L) & $595 \mathrm{kV}$ \\
Nominal SM Voltage & $1.78 \mathrm{kV}$ \\
Number of SMs per Arm (N) & 599 \\
SM Capacitor & $8.5 \mathrm{mF}$ \\
Nominal Stored Energy & $38.5 \mathrm{~kJ} / \mathrm{MVA}$ \\
Peak SM Voltage Limit & $2 \mathrm{kV}$ \\
Peak Arm Current Limit & $1.35 \mathrm{kA}$ \\
Arm Modulation Index Limits & 0.05 \\
Arm Inductor & $0.2 \mathrm{pu}(104.4 \mathrm{mH})$ \\
Transformer Leakage Reactance & $0.14 \mathrm{pu}(208.9 \mathrm{mH})$ \\
IGBT Module & $5 \mathrm{SNA} 1200 \mathrm{E} 330100$ \\
Max Coolant Temperature & $50{ }^{\circ} \mathrm{C}$ \\
\hline
\end{tabular}

The controlled circulating current in the example converter is comprised of $2 n d$ and $4 t h$ harmonic and has been optimised to minimise the peak arm current flowing through the converter. The resulting arm current waveforms within the converter are shown in Figure 2. Running such a circulating current requires a converter controller with control over individual arm currents to be implemented. By utilising this circulating current waveform the active power limit imposed by the peak arm current limit can be extended by approximately $30 \%$. However due to the increased energy deviation of the SMs caused by such a circulating current this technique causes some design penalties, such as a slightly increased number of SMs or larger SM capacitors.

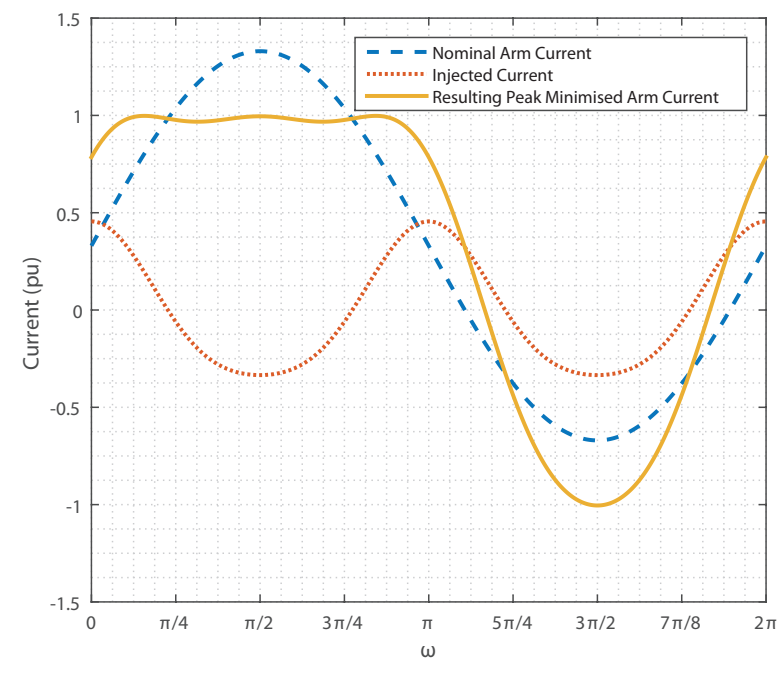

Figure 2: Peak Arm Current Reduction

By utilising these techniques MMC P/Q envelopes such as the one shown in Figure 3 might be realised. A reduction in the reactive power capability requirement in the overload region may lessen the design penalty of introducing such overload capacity, as the operating point at peak rated power and rated capacitive power factor is one of the main design constraints in dimensioning MMCs [5].

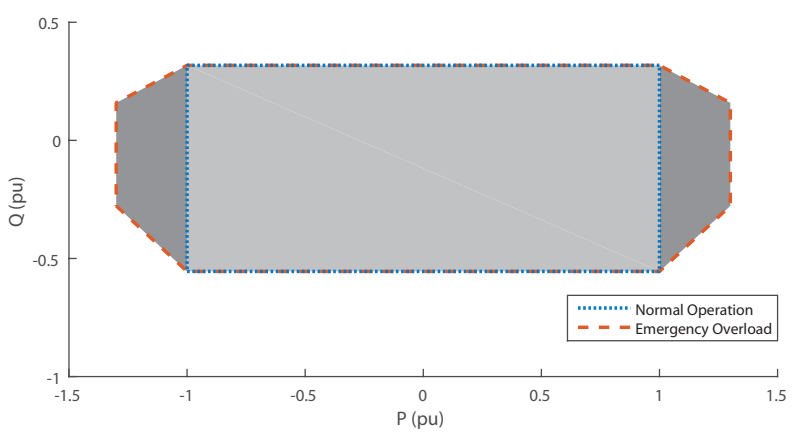

Figure 3: PQ Envelope

A simulation of the converter ramping into the emergency overload region is shown in Figure 4. As the converter enters the overload region the circulating current controller is activated, suppressing the peak arm current to within the same level as seen during rated power in normal operation.

Due to the low switching frequency operation of the IGBT modules within MMCs, the losses are such that the power 

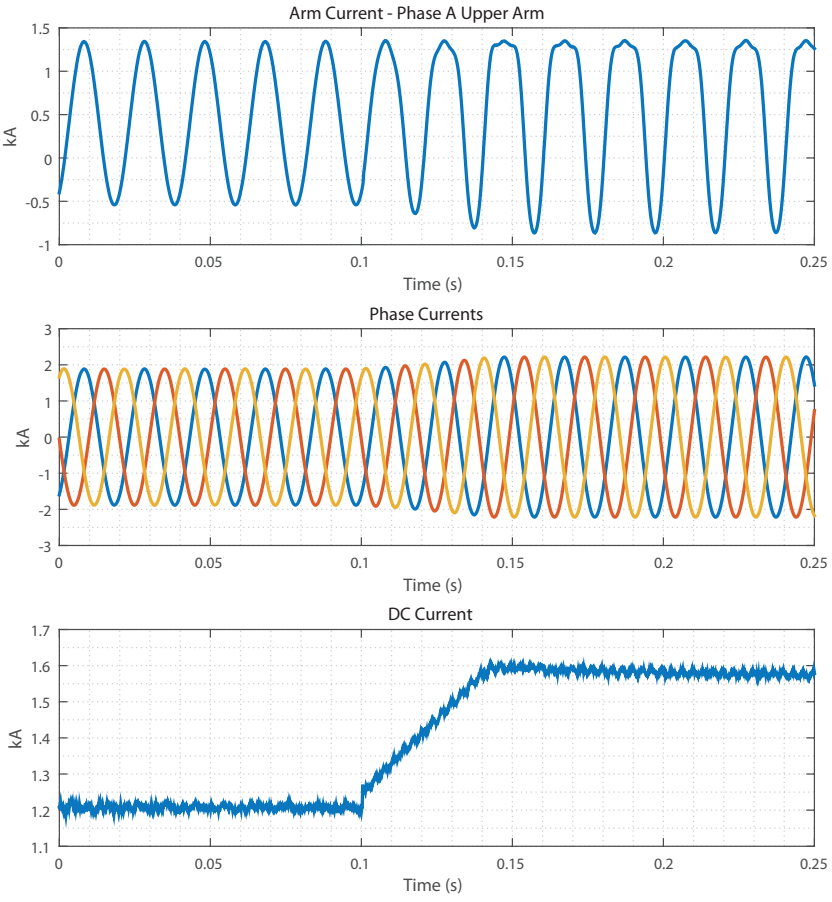

Figure 4: Converter Ramping from 1pu Active Power to 1.3pu Overloaded Operation

range is not limited by the junction temperature limit but by the SOA of the devices [7, 8]. However because of increased losses due to the higher RMS currents this may not be the case during overloaded operation.

\section{THERMAL DYNAMICS}

\section{A. Modeling}

1) Thermal Model of IGBT Module: A thermal model of a water-cooled device has been developed using the Finite Element Method (FEM) electronics thermal simulation package ANSYS IcePak. The module used is from ABB Semiconductors [9] and is used for several of their high power devices, with voltage ratings in the $3.3 \mathrm{kV}-4.5 \mathrm{kV}$ range and current ratings in the region of 1000-1800 A. The module modelled within ANSYS IcePak is shown in Figure 5.

The thermal modelling of a similar heat sink mounted IGBT module and validation against experimental results has been extensively covered in [10]. The thermal model within this study has been compared against the results presented in [10], and agrees with close approximation.

Internally the device consists of 24 IGBT dies and 12 diode dies connected by internal bus bars and bond wires. The diode dies are located closest to the centre of the device. In the model it is assumed that all heat flow is from the active junctions to the cooling liquid of the heat-plate and that any heat flow from the junction to ambient air is negligible, for this reason the plastic case, bond wires and internal bus bars of the module are not included in the model. The power losses are modelled as 2-D power sources, dissipating a fixed amount of power, placed upon the top surface of each die. The dies within the module are assumed to equally share the overall power loss

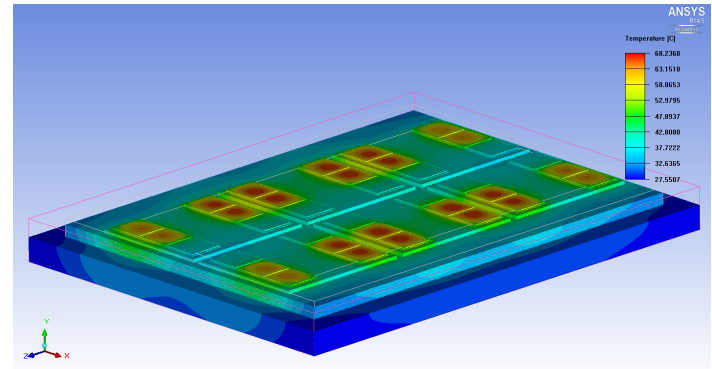

(a) Heat Dissipated at IGBT Dies

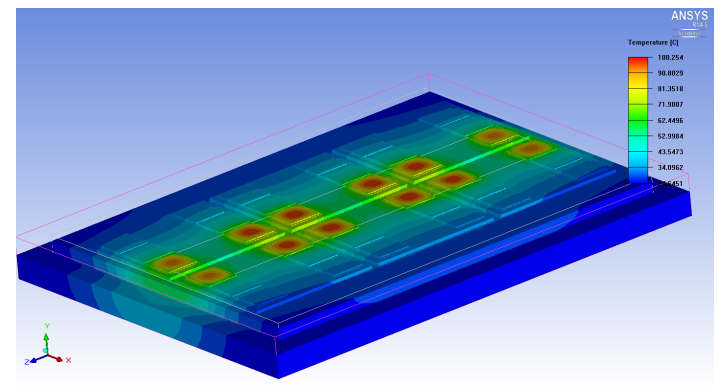

(b) Heat Dissipated at Diode Dies

Figure 5: IGBT module with power sources dissipating heat at the silicon dies

within the module due to the positive temperature coefficient of the on-state voltage of each die.

The junction temperatures were measured at the geometric centre of each silicon die. Due to the internal construction of the device there is a varying amount of cross coupling between the dies which leads to an imbalance between junction temperatures of individual dies within the module. The junction temperature measurements presented in this study are an average of the junction temperatures measured at each IGBT or diode die within the module.

The transient thermal impedance response curves of the module to both sets of dies being heated are shown in Figure 6. To derive thermal models suitable for use within the Matlab/Simulink model the transient thermal impedance curves are fitted to a finite series of exponential terms in the form of (2). The Laplace transform is then applied to this finite series to give a transfer function suitable for use in Matlab/Simulink. The extracted values from the curves are given in Table II.

$$
Z_{t h}(t)=\sum R_{i} \cdot\left(1-\exp \left(\frac{-t}{\tau_{i}}\right)\right)
$$

The short-term thermal response of the system is dominated by the response of the silicon dies themselves, which heat up within several fundamental cycles of converter operation. However the thermal path also contains elements with longer time constants, such as the devices base-plate and the heat-sink itself.

2) Power Loss Modeling: The power losses within the module are estimated using a look-up table method, based upon the current waveforms through each device, using data extracted from the manufacturers data-sheet. This method is 


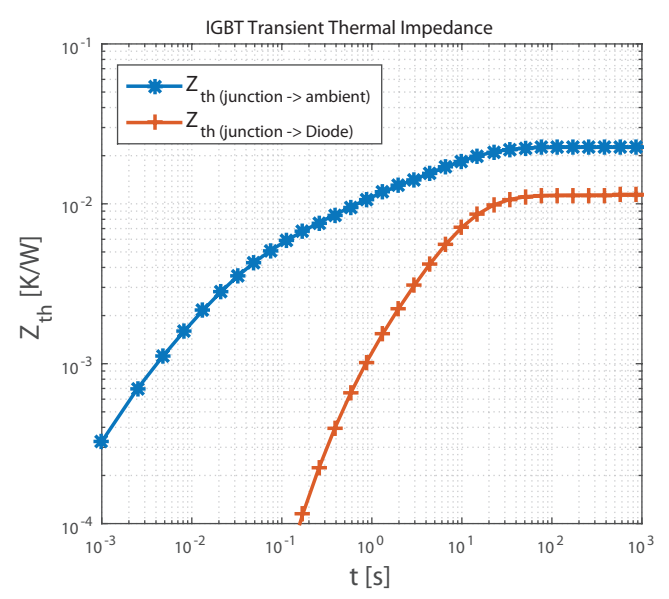

(a) IGBT Dies Heated

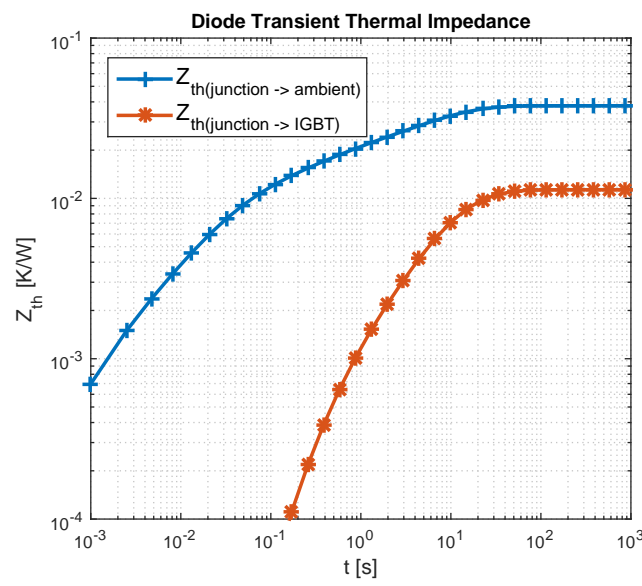

(b) Diode Dies Heated

Figure 6: Transient Thermal Impedance Response of IGBT Module

Table II: Transient Thermal Impedance Values

\begin{tabular}{c|c|cccc}
\hline \multicolumn{1}{c}{$\mathrm{i}$} & & 1 & 2 & 3 & 4 \\
\hline \multirow{2}{*}{ IGBT to Ambient } & $R_{i}(K / k W)$ & 3.6450 & 4.2970 & 5.406 & 11.37 \\
& $\tau_{i}(s)$ & 0.0141 & 0.117 & 1.026 & 10.8 \\
\hline \multirow{2}{*}{ IGBT to Diode } & $R_{i}(K / k W)$ & 1.337 & 7.386 & 3.192 & 5.120 \\
& $\tau_{i}(s)$ & 5.45 & 8.65 & 19.43 & 122.4 \\
\hline \multirow{2}{*}{ Diode to Ambient } & $R_{i}(K / k W)$ & 5.617 & 10.04 & 9.633 & 15.7 \\
& $\tau_{i}(s)$ & 0.0102 & 0.0839 & 1.050 & 9.621 \\
\hline \multirow{2}{*}{ Diode to IGBT } & $R_{i}(K / k W)$ & 1.303 & 3.003 & 5.247 & 7.015 \\
& $\tau_{i}(s)$ & 2.872 & 2.753 & 6.769 & 14.610 \\
\hline
\end{tabular}

presented in [11], and has been updated to account for junction temperature dependent changes in the devices characteristics.

\section{B. Steady State Junction Temperatures}

In an MMC operating at close to unity power factor it has been shown that the lower IGBT within each half-bridge SM is placed under significantly more thermal stress than the upper IGBT [8] . For this reason, only estimated results for the lower IGBT within a SM are shown. The power losses and steadystate junction temperatures within the lower IGBT are shown in Figure 7.

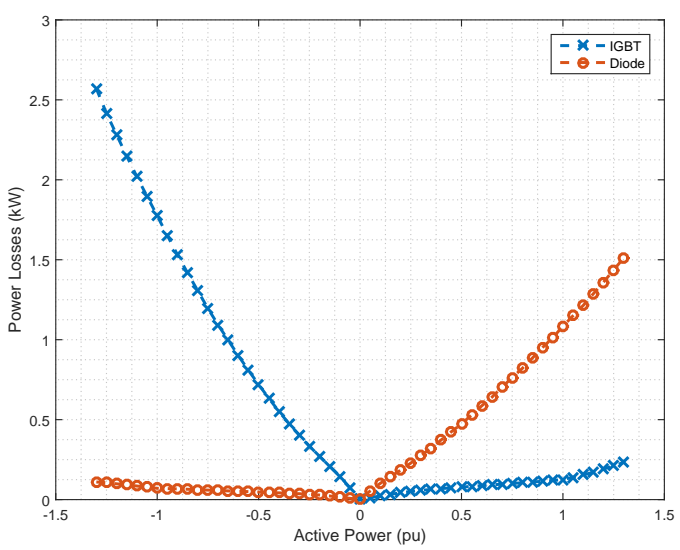

(a) Power Losses

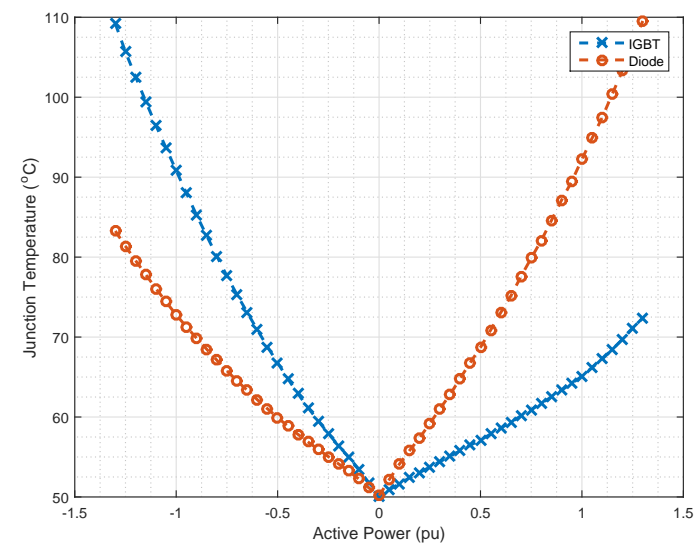

(b) Junction Temperature

Figure 7: Power Losses and Junction Temperatures within the Lower IGBT Module in an MMC SM

The highest junction temperature reached during normal operation is $92^{\circ} \mathrm{C}$, indicating good utilisation of the device [12]. As the converter increases to 1.3 pu power, the junction temperature peaks at $110^{\circ} \mathrm{C}$ which is approaching the $125^{\circ} \mathrm{C}$ limit of the device and could be considered a high risk temperature.

\section{Dynamic Thermal Overload Rating}

For HVDC applications where the cost of failure is high, it is likely that significant safety margins will be imposed on the device junction temperature. This safety margin should account for variation in the device characteristics, as well as lifetime degradation of the device and its cooling path. A junction temperature limit of $100^{\circ} \mathrm{C}$ has been chosen for the example converter. This gives a margin of approximately $9^{\circ} \mathrm{C}$ of thermal headroom to exploit during overloaded operation, assuming a pre-overload operation at 1 pu active power and a coolant at maximum design temperature.

From Figure 7 it can be seen that this will result in a steady state overload capability of $1.14 \mathrm{pu}$. By exploiting the elements of the cooling path of the IGBTs with longer thermal 
time constants, namely the base-plate and heat-sink, it may be possible to temporarily breach this steady-state limit whilst keeping below the specified junction temperature limit. This may potentially be useful for providing short-term overload capacity in response to fast system events with a lower steadystate overload capacity also available.

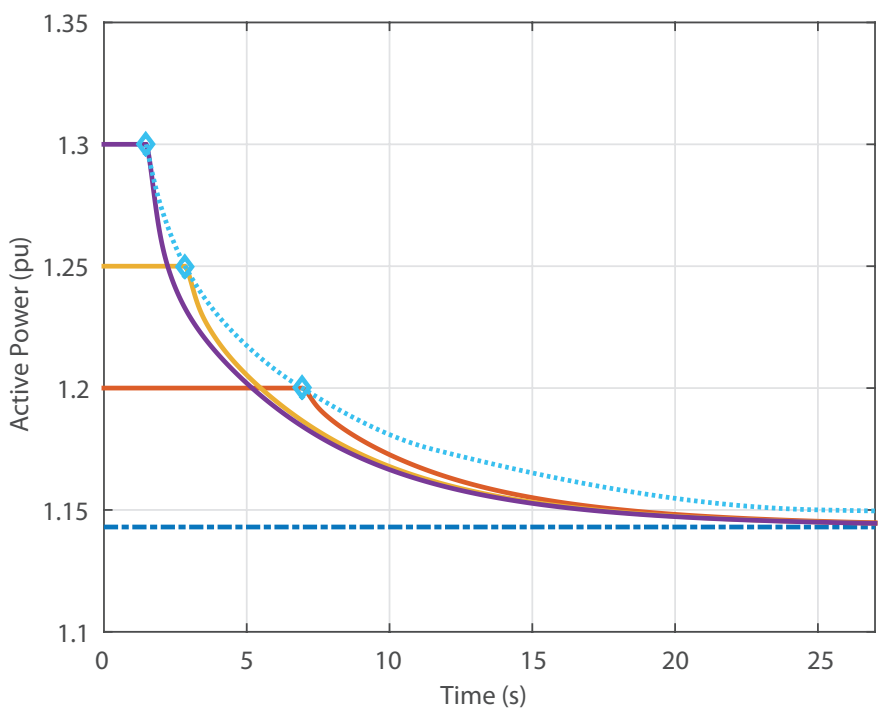

Figure 8: Transient Overload Rating with a Junction Temperature Limit of $100{ }^{\circ} \mathrm{C}$ - Rectifier Operation

Using an averaged model of the power losses within the converter and the transient thermal model of the IGBT device, the transient overload rating of the example converter has been determined and is shown in Figure 8. The plot shows the power curves that the converter can follow and still keep the peak junction temperature of the device below the specified limit of $100^{\circ} \mathrm{C}$ during overloaded operation. The dotted line shows the interpolated point where the converter's power would have to be ramped back down to prevent over-heating of the devices. The converter is capable of maintaining the maximum overload rating for a duration of $\sim 1.5$ seconds, with the transient power limit curve showing an approximately exponential decay from this point.

A worst case of operating a 1 pu active power prior to overloaded operation was assumed for the given curves, this means the converter has the minimum amount of available thermal overhead before moving into the overload region. The rating will be different depending on whether the converter is operating as an inverter or rectifier because of the thermal imbalance between the diode and IGBT junction temperatures within the module. In a point-to-point link the worst case will be the limiting factor, however in multi-terminal networks this may not be the case.

Beyond the thermal limits of the power electronic devices additional system components will impose limitations on increased power flow though the system. These additional elements will include the AC side transformers, DC cable/overhead line, as well as the internal bus bars and electrical terminals of the converter. The results here are shown for the maximum ambient coolant temperature that the converter has been specified for of $50^{\circ} \mathrm{C}$. Additional overload capability may be achieved by increasing the power of the cooling system to reduce the ambient coolant temperature. The actual coolant temperature will be dependent on the converter loading and the weather conditions at the converter station.

\section{Simulation Results}

To demonstrate the potential usefulness of short term overload capability simulation results of a converter responding to an under-frequency event on the AC system are shown. The power set-point of the converter during the frequency event is regulated by a simple droop controller. This set point is then further adjusted by an overload controller, implemented as a simple integral gain, to maintain the maximum junction temperature reached to below the specified limit of $100^{\circ} \mathrm{C}$. This overload controller is only activated when the junction temperature limit is breached. A schematic of this scheme is shown in Figure 9.

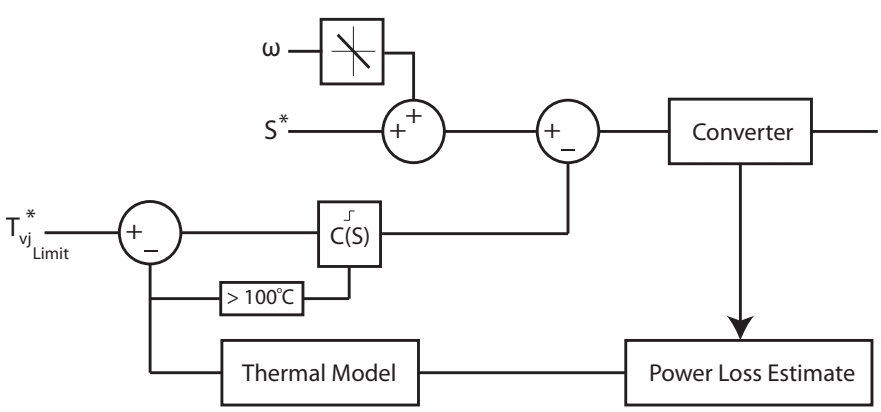

Figure 9: Converter Power Controller with Droop Gain and Overload Controller

Simulation results of the converter response to a fixed underfrequency event, with variation in the droop gains, are shown in Figure 10. The frequency event is implemented on an ideal voltage source in the simulation and is independent of the converter power output.

Results indicate that the full overload capacity of the converter is only available during the first two seconds of overload operation, as in the case of the $0.6 \mathrm{pu} / \mathrm{Hz}$ and 0.8 $\mathrm{pu} / \mathrm{Hz}$ droop response. This is in agreement with the transient overload rating shown in Figure 8.

In the other droop cases the junction temperature has nearly reached the $100^{\circ} \mathrm{C}$ limit by the time the droop characteristic is constrained by the overload controller. This indicates that if converters are designed with a dynamic overload rating it may be beneficial to use this short-term overload capacity in a one-shot manner as soon as the frequency event is detected. This may be useful in quickly delivering additional power to support the grid during the initial portion of a frequency event when the Rate Of Change Of Frequency (ROCOF) is greatest with the steady-state overload capacity used to provide primary reserve support after the dynamic capacity has been used.

\section{CONCLUSION}

The thermal dynamics within the converter station have been discussed. The concept of using controlled circulating currents to provide overload capacity has been presented. In 

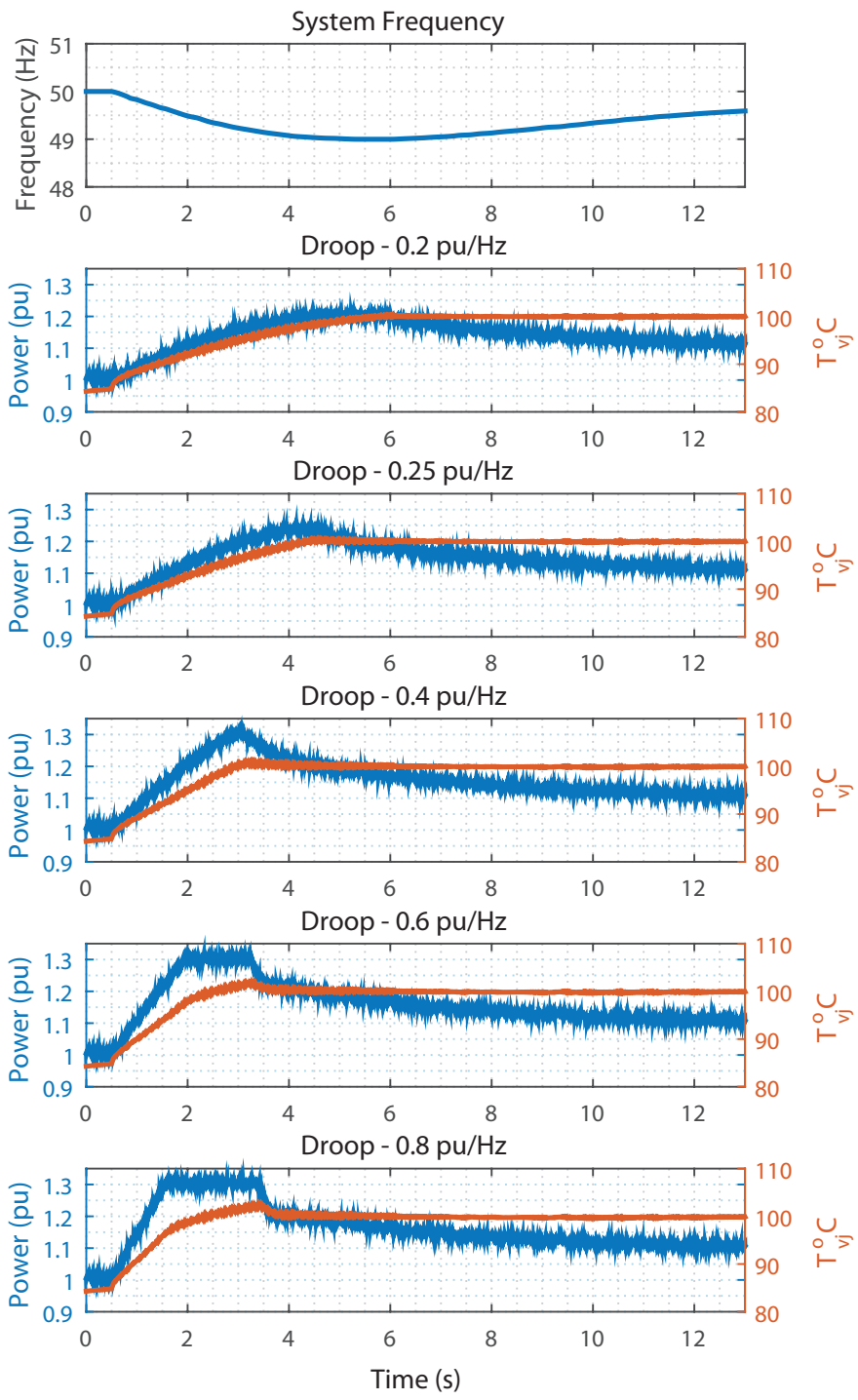

Figure 10: Response of Converter to Under-Frequency Event

cases where the IGBT device junction temperature becomes the limiting factor the concept of dynamically rating the converter to provide short term overload capacity is presented. Simulation results have been presented which show how these techniques may be applied during system disturbances.

\section{REFERENCES}

[1] A. Lesnicar and R. Marquardt, "An innovative modular multilevel converter topology suitable for a wide power range," in Power Tech Conference Proceedings, 2003 IEEE Bologna, vol. 3, 2003, pp. 6 pp. Vol.3-.

[2] X. Aidong, W. Xiaochen, H. Chao, J. Xiaoming, and L. Peng, "Study on overload capability and its application of hvdc transmission system in china southern power grid," in Power Engineering Society Conference and Exposition in Africa, 2007. PowerAfrica '07. IEEE, July 2007, pp. 1-4.

[3] R. Dass, B. Linden, S. Rinaldo, and S. Cheung, "Operation experience from bulk power HVDC links from three gorges complex," Cigre 2006, 2006.
[4] B. Jacobson, P. Karlsson, G. Asplund, L. Harnefors, and T. Jonsson, "VSC-HVDC Transmission with Cascaded Two-Level Converters," in CIGRE, 2010.

[5] C. Oates, "Modular multilevel converter design for vsc hvdc applications," Emerging and Selected Topics in Power Electronics, IEEE Journal of, vol. PP, no. 99, pp. 1-1, 2014.

[6] S. Norrga, L. Ängquist, and K. Jlves, "Operating region extension for multilevel converters in hvdc applications by optimisation methods," in AC and DC Power Transmission (ACDC 2012), 10th IET International Conference on, 2012, pp. 1-6.

[7] Q. Tu and Z. Xu, "Power losses evaluation for modular multilevel converter with junction temperature feedback," in Power and Energy Society General Meeting, 2011 IEEE, July 2011, pp. 1-7.

[8] P. Judge, M. Merlin, P. Mitcheson, and T. Green, "Power loss and thermal characterization of igbt modules in the alternate arm converter," in Energy Conversion Congress and Exposition (ECCE), 2013 IEEE, 2013, pp. 17251731.

[9] ABB Semiconductors. Datasheets available online. [Online]. Available: http://www.abb.com/semiconductors

[10] U. Drofenik, D. Cottet, A. Müsing, J. M. Meyer, and J. W. Kolar, "Modelling the thermal coupling between internal power semiconductor dies of a water-cooled 3300V/1200A HiPak IGBT module," in Proceedings of Power Conversion and Intelligent Motion Conference, 2007.

[11] Z. Luo, "A thermal model for igbt modules and its implementation in a real time simulator," Ph.D. dissertation, University of Pittsburgh, 2002.

[12] K. Ma, A. Bahman, S. Beczkowski, and F. Blaabjerg, "Complete loss and thermal model of power semiconductors including device rating information," Power Electronics, IEEE Transactions on, vol. PP, no. 99, pp. 1-1, 2014. 